\title{
Effects of fluoxetine on behavior, antioxidant enzyme systems, and multixenobiotic resistance in the Asian clam Corbicula fluminea
}

\author{
Huihui Chen, Jinmiao Zha*, Lilai Yuan, Zijian Wang* \\ State Key Laboratory of Environmental Aquatic Chemistry, Research Center for Eco-Environmental Sciences, Chinese Academy of Sciences, Beijing, People's Republic of China
}

\section{H I G H L I G H T S}

- $G R, T R, A B C B 1, A B C C 1$, and $A B C G 2$ genes were identified in the clam.

- The siphoning behavior of the clam was inhibited by FLX.

- FLX exposure induced oxidative effects to the clam.

- The expressions of MXR system genes were altered by FLX.

\section{A R T I C L E I N F O}

\section{Article history:}

Received 4 April 2014

Received in revised form 19 August 2014

Accepted 21 August 2014

Available online 19 September 2014

Handling Editor: Caroline Gaus

\section{Keywords:}

Fluoxetine

C. fluminea

Siphoning behavior

Antioxidant enzymes

Multixenobiotic resistance

\begin{abstract}
A B S T R A C T
Fluoxetine (FLX), a selective serotonin reuptake inhibitor, is widespread in aquatic environments. Despite its reported effects on behavior and reproduction in aquatic species, little is known about the effects of FLX on cellular detoxification and defense system in bivalves. Here, the adult Asian clam (Corbicula fluminea) was exposed to $0.5,5$, and $50 \mu \mathrm{g} \mathrm{L}{ }^{-1}$ FLX for $30 \mathrm{~d}$. Siphoning behavior was inhibited by treatment with $50 \mu \mathrm{g} \mathrm{L}^{-1} \mathrm{FLX}$. Additionally, superoxide dismutase (SOD) activity in the gills and digestive glands significantly decreased $(p<0.05)$ with 5 and $50 \mu \mathrm{g} \mathrm{L}^{-1} \mathrm{FLX}$ treatments, whereas catalase (CAT) activity and malondialdehyde (MDA) content markedly increased $(p<0.05)$. Moreover, transcription of thioredoxin reductase $(T R)$, glutathione peroxidase (GPX) and Glutathione S-transferase pi class (GSTpi) was significantly upregulated $(p<0.05)$, whereas glutathione reductase $(G R)$ was markedly downregulated $(p<0.05)$. These findings suggest that FLX affects behavior and induces oxidative stress in C. fluminea. The downregulation of ATP-binding cassette $(A B C)$ transportor genes $(A B C B 1, A B C C 1$ and $A B C G 2$ ) transporter genes indicated that FLX might suppress the multixenobiotic resistance (MXR) system in C. fluminea. Our results provide new insights into the adverse effects of FLX on the cellular detoxification and MXR system of $C$. fluminea.
\end{abstract}

(c) 2014 Elsevier Ltd. All rights reserved.

\section{Introduction}

Pharmaceuticals are a large and diverse collection of bioactive chemicals that are used in human and veterinary medicine (Kim

Abbreviations: $\mathrm{ABC}$, ATP-binding cassette; $\mathrm{ABCB} 1$ or MDR1, multidrug resistance protein 1; $A B C C 1$ or MRP1, multidrug resistance-associated protein 1; ABCG2, breast cancer resistance protein; AChE, acetylcholinesterase; CAT, catalase; GPx, glutathione peroxidase; GR, glutathione reductase; GSTpi, Glutathione S-transferase pi class; GSH, glutathione; MDA, malondialdehyde; MXR, multixenobiotic resistance; P-gp, P-glycoprotein; ROS, reactive oxygen species; SOD, superoxide dismutase; TR, thioredoxin reductase.

* Corresponding authors. Address: State Key Laboratory of Environmental Aquatic Chemistry, Research Center for Eco-Environmental Sciences, Chinese Academy of Sciences, 18 Shuangqing Road, Haidian District, Beijing 100085, People's Republic of China. Tel.: +86 10 62849107; fax: +86 1062849140 .

E-mail addresses: jmzha@rcees.ac.cn (J. Zha),wangzj@rcees.ac.cn (Z. Wang). et al., 2007). Due to human use, large quantities of pharmaceuticals have been discharged into aquatic environments (Blair et al., 2013; Liu and Wong, 2013). Serotonin reuptake inhibitors (SSRIs), a class of antidepressant, are the most studied pharmaceuticals in the context of aquatic systems (Fent et al., 2006). These drugs have been reported to affect reproduction, foraging, stress responses, and aquatic organism locomotion (Brooks et al., 2003). Fluoxetine (FLX) is the most widely prescribed SSRI drug, and FLX contamination is widespread in rivers, surface water, and sewage treatment plant effluents in areas where it is used (Gonzalez-Rey and Bebianno, 2013). Reported FLX concentrations in surface water in Canada (Metcalfe et al., 2003), Croatia (Gros et al., 2006), and the USA (Bringolf et al., 2010) were approximately 46, 66, and $111 \mathrm{ng} \mathrm{L}^{-1}$, respectively. Recently, FLX was detected in $25 \%$ of the water samples collected from various locations in the USA at an average concentration of $65 \mathrm{ng} \mathrm{L}^{-1}$ (Ferrer and Thurman, 2012). 
Because the FLX concentrations measured in the environment are much lower than that which produces a therapeutic effect in humans, it seems unlikely to pose a risk of acute toxic effects (Carlsson et al., 2006). However, previous studies have reported that FLX can induce toxic effects on aquatic organisms at environmental concentrations (Brooks et al., 2003; Pery et al., 2008; Sánchez-Argüello et al., 2009; Dzieweczynski and Hebert, 2012; Hazelton et al., 2013). The acute ( $48 \mathrm{~h}$ ) median lethal concentration (LC50) value for fathead minnows (Pimephales promelas) is approximately $2 \mathrm{mg} \mathrm{L}^{-1}$ (Ferrari et al., 2004). Additionally, FLX can affect bivalve behavior and reproduction. Lazzara et al. (2012) reported decrease in spawning in zebra mussels (Dreissena polymorpha) after 6-d exposure to 20-200 ng L ${ }^{-1}$ FLX. In another study, the burrowing behavior of freshwater mussels (Lampsilis fasciola) was inhibited after exposure to $22.3 \mu \mathrm{g} \mathrm{L}^{-1}$ FLX for $67 \mathrm{~d}$ (Hazelton et al., 2013). Gonzalez-Rey and Bebianno (2013) reported that the acetylcholinesterase (AchE) activity of mussels (Mytilus galloprovincialis) was repressed after $75 \mathrm{ng} \mathrm{L}^{-1}$ FLX treatment for $15 \mathrm{~d}$. Thus far, the acute toxicity and ethology of FLX on bivalves have been well investigated, but its effects on the cellular detoxification and defense systems are not well documented.

FLX has been reported to affect antioxidant system in mice and mussel (Djordjevic et al., 2011; Gonzalez-Rey and Bebianno, 2013). Oxidative stress is characterized by the imbalance when xenobiotic-mediated enhancement of reactoxygen species (ROS) exceed exposed aerobic organism's antioxidant defense mechanisms (Ren et al., 2013). Antioxidant enzymes, such as superoxide dismutase (SOD), catalase (CAT), glutathione peroxidase (GPX) and Glutathione S-transferase (GST) protect organisms against ROS. Malondialdehyde (MDA) is a product of the decomposition of unsaturated fatty acid peroxides that are generated from ROS and is usually rapidly degraded by ROS (Marnett, 1999; Stancliffe et al., 2011). Thioredoxin reductase (TR), glutathione reductase (GR), GPx, and GST are the primary antioxidant enzymes of the thioredoxin and glutathione systems, which are found in animals, plants, and microorganisms (Meister and Anderson, 1983). The fluctuation of these antioxidant enzymes and MDA have been used successfully as oxidative stress and early-warning bio-indicators of cellular hazards in mussels species (Contardo-Jara et al., 2011; Gonzalez-Rey and Bebianno, 2013; Chen et al., 2014).

The cellular multixenobiotic resistance (MXR) system represents a broad-scale defense mechanism that protects cells and organisms against endogenous and exogenous toxicants (Epel et al., 2008). MXR is mediated by membrane transport proteins from the ATP binding cassette (ABC) protein family, which recognize a wide variety of potential xenobiotics as substrates, and pump them out of the cell in an energy-dependent, ATP-driven process (Navarro et al., 2012). The primary ABC proteins with MXR-related functions include P-gp (P-glycoprotein, gene symbol $A B C B 1$ ), MRP1 (multidrug resistance-associated protein 1, gene symbol $A B C C 1$ ), and BCRP (breast cancer resistance protein, gene symbol $A B C G 2$ ) (Leslie et al., 2005). Evidence indicates that the MXR system acts as a cellular defense mechanism in aquatic organisms (Bard, 2000; Contardo-Jara et al., 2008).

The freshwater bivalve Corbicula fluminea (Müller, 1774), commonly known as the Asian clam, is native to Southeast Asia (Araujo et al., 1993). As a benthonic freshwater bivalve, C. fluminea is sensitive to aquatic pollutants and has been used as a test organism in field and laboratory studies to monitor environmental changes and contamination (Vasconcelos et al., 2009; Frenzel et al., 2012; Chen et al., 2013). This study mainly investigated the effects of FLX on behavior, cellular detoxification, and the MXR system in the bivalve $C$. fluminea. Adult $C$. fluminea were exposed to FLX for $30 \mathrm{~d}$, after which multi-endpoints were measured, including siphoning behavior, the levels of three stress biomarkers: SOD, CAT and MDA, the expression of thioredoxin and glutathione systems genes ( $T R, G R, G P x$, and GSTpi), and $A B C$ transportor genes $(A B C B 1, A B C C 1$, and $A B C G 2)$ in gills and digestive gland.

\section{Materials and methods}

\subsection{Chemical}

Fluoxetine hydrochloride (product number F0750, purity $>98 \%$, CAS No. 56296-78-7) was purchased from TCI (Tokyo Chemical Industry Co., Ltd., Tokyo, Japan).

\subsection{Experimental animals}

Sexually mature clams (C. fluminea) were collected from Hongze Lake (Jiangsu province, China) and were transferred to the laboratory in water tanks with continuous aeration. There, clams were kept at constant temperature $\left(20 \pm 1^{\circ} \mathrm{C}\right), \mathrm{pH}(7.8 \pm 0.2)$, and oxygen saturation $(96 \% \pm 2 \%)$ in 50 L glass aquaria $(8-10 \mathrm{~cm}$ water depth, without sediment) on a 12 h: 12 h (light: dark) cycle. The clams were fed with single-celled algae Chlorella vulgaris and Scenedesmus obliquus once per day.

\subsection{FLX exposure assays}

After $14 \mathrm{~d}$ of acclimation, the clams (40 clams per aquaria, average length of $20.56 \pm 2.05 \mathrm{~mm}$ ) in the experimental groups were exposed to FLX. The nominal FLX concentrations in the water were $0,0.5,5$, and $50 \mu \mathrm{g} \mathrm{L}^{-1}$. All control or treated groups were in triplicate. The water was changed daily, at which time FLX was added. The mortalities of all groups were recorded during the exposure. At least 3 independent biological replicates for each treatment were harvested at the end of the exposure. The gills and digestive glands of the control and treated groups were collected and stored individually at $-80{ }^{\circ} \mathrm{C}$ for future analyses. The following equation was used to estimate condition index (CI) based on the weights of 10 clams from each group (Gonzalez-Rey and Bebianno, 2013):

$$
\mathrm{CI}(\%)=\left(W_{s} / W_{t}\right) \times 100
$$

where $W_{s}$ is the wet weight of all soft tissue, and $W_{t}$ is the wet weight of the entire body tissue, including the shell.

\subsection{FLX concentrations in water}

The FLX concentrations were quantified once per week immediately after tanks were dosed. FLX concentrations were measured using ultra performance liquid chromatography tandem mass spectrometry (UPLC-MS/MS) as described by Batt et al. (2008). The detailed method was showed in Supplemental Material. The analyzed concentrations (mean \pm standard deviation, and \% of nominal concentration) of FLX in the test solutions during the exposure period were $0.48 \pm 0.35 \mu \mathrm{g} \mathrm{L}^{-1}$ (96\%), $4.42 \pm 0.38 \mu \mathrm{g} \mathrm{L}^{-1}$ (88\%), and $42.66 \pm 2.35 \mu \mathrm{g} \mathrm{L}{ }^{-1}(85 \%)$ for the $0.5,5$, and $50 \mu \mathrm{g} \mathrm{L}^{-1}$ treatments, respectively. Nominal FLX values are used in the present study.

\subsection{Siphoning behavior}

The siphoning rate was measured using the adapted method described by Cooper and Bidwell (2006), which is based on the loss of neutral red dye particles from the water column due to filtration by the clams. Immediately following the FLX exposure experiments, 5 clams from each exposure concentration were placed in $200 \mathrm{~mL}$ beakers containing $100 \mathrm{~mL}$ of neutral red solution ( $1 \mathrm{mg} \mathrm{L}^{-1}$ in dechlorinated tap water with no added FLX) and 
allowed to siphon for $2 \mathrm{~h}$. Just prior to placing the clams in the solution, $1 \mathrm{~mL}$ aliquots of water were removed from each beaker, and the neutral red concentration was determined by measuring the optical density at $530 \mathrm{~nm}$ using a spectrophotometer. Standards of neutral red solution were measured along with the samples and used to generate a standard curve. The filtration rate was calculated using the equation of Cooper and Bidwell (2006):

$m=\left[\frac{M}{n t}\right] \log \left(\frac{C_{0}}{C_{t}}\right)$

where $M$ is the volume of the test solution, $n$ is the number of clams used, $t$ is the time in hours, $C_{0}$ is the initial concentration of the dye, $C_{t}$ is the concentration of the dye at time $t$, and $m$ is the filtration rate $(\mathrm{mL} / \mathrm{animal} / \mathrm{h})$.

\subsection{Activity of antioxidant enzymes and MDA assay}

Approximately $200 \mathrm{mg}$ of the gills and digestive gland from 5 clams of each experimental group was ground in a $1 \mathrm{~mL}$ centrifuge tube with $0.5 \mathrm{~mL}$ RIPA Lysis buffer (Beyotime Institute of Biotechnology, China) using a pestle on ice. The homogenate was centrifuged at $12000 \mathrm{rpm}$ for $10 \mathrm{~min}$, and the supernatant was then collected into a new $1.5 \mathrm{~mL}$ tube. The protein content of the supernatant was determined using the BCA Protein Assay Kit (Beyotime Institute of Biotechnology, Shanghai, China), and the samples were frozen at $-80^{\circ} \mathrm{C}$ until further analysis. The activities of antioxidant enzymes SOD and CAT, and the MDA content were analyzed in the gills and digestive glands using Assay Kit (Beyotime Institute of Biotechnology, China) according to the manufacturer's protocols. The detailed methods were showed in Supplemental Material.

\subsection{Identification of partial $c D N A$ sequences from $C$. fluminea}

Total RNA was isolated from the digestive gland of adult $C$. fluminea (Non-experimental groups) using the SV Total RNA Isolation System (Promega, Fitchburg, WI, USA) according to the manufacturer's protocols. The cDNA was synthesized with $2 \mu \mathrm{g}$ RNA after RQ1 DNase treatment (Promega, USA) using random hexamers and M-MLV reverse transcriptase (Promega, USA) according to the manufacturer's instructions. The synthesized cDNA was stored at $-20^{\circ} \mathrm{C}$ until further use.

To obtain cDNA fragments of the studied genes of $C$. fluminea, primer pairs were designed based on the assembled sequence of the $C$. fluminea transcriptome (Chen et al., 2013). The RT-PCR primers are shown in Supplemental Material Table S1. For RT-PCR assays, the cDNA was amplified with GoTaq ${ }^{\circledR}$ GreenMaster Mix (Promega, USA) in a Veriti thermal cycle system (Life Technologies, USA). The sequences were compared to the corresponding references for mollusks in Genbank using NCBI BLAST (http:// www.ncbi.nlu.nih.gov/blast/Blast.cgi).

\subsection{Relative quantification by real-time $P C R$}

The total RNA was isolated, and cDNA was synthesized according to the methods described above. The expression of the tested genes (TR, GR, GPX, GSTpi, $A B C B 1, A B C C 1$, and $A B C G 2)$ was determined using an $A B I 7500$ real-time quantitative PCR system (Life Technologies, USA) according to a previously described method (Chen et al., 2013). The $\beta$-actin gene of $C$. fluminea was used as an endogenous control. Supplemental Material Table S1 lists the primer pairs used for real-time PCR. The results of real-time quantitative PCR were analyzed using the delta-delta $\mathrm{Ct}$ method (Schmittgen and Livak, 2008). The experiments were performed in triplicate.

\subsection{Statistical analysis}

Statistical analyses were performed with SPSS (version 16.0) and OriginPro (version 8.0) software. The experimental data were checked for homogeneity of variance using Levene's test. The significance of differences between exposed and control samples was determined using 1-way ANOVA followed by Dunnett's test for multiple comparisons. All quantitative data are expressed as mean \pm standard error of the mean (SEM). The threshold for statistical significance was $p<0.05$.

\section{Results}

\subsection{Identification of partial cDNA sequences}

Partial cDNA fragments of $G R, T R, A B C B 1, A B C C 1$, and $A B C G 2$ were isolated and cloned from adult $C$. fluminea. The sequences of the 5 genes have been submitted to the NCBI GenBank database (GR (KF275127, 879 bp), TR (KF275126, 966 bp), ABCB1 (KJ001772, $684 \mathrm{bp}$ ), $A B C C 1$ (KJ027659, $708 \mathrm{bp}$ ), and ABCG2 (KJ001773, $354 \mathrm{bp})$ ). The amino acid sequences were highly conserved among all sequences analyzed (Table 1 ).

Table 1

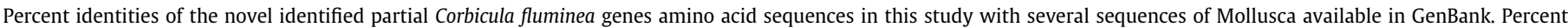
identities were obtained with NCBI Blastx.

\begin{tabular}{|c|c|c|c|}
\hline Proteins and Species & NCBI access. No. & Description & \% Identity \\
\hline \multicolumn{4}{|l|}{ GR } \\
\hline Crassostrea gigas & gb|ЕКC35400.1| & Glutathione reductase & 72 \\
\hline \multicolumn{4}{|l|}{ TR } \\
\hline Crassostrea gigas & gb|ЕКC27867.1| & Thioredoxinreductase 3 & 78 \\
\hline \multicolumn{4}{|l|}{$\mathrm{ABCB} 1$} \\
\hline Crassostrea gigas & gb|EKC23020.1| & Multidrug resistance protein 1 & 61 \\
\hline Mytilus galloprovincialis & $\mathrm{gb} \mid \mathrm{ABO36618.1|}$ & Multidrug resistance protein & 65 \\
\hline Azumapecten farreri & gb|ACL80139.3| & P-glycoprotein-like protein & 64 \\
\hline Perna viridis & gb|AFV15804.1| & P-glycoprotein & 58 \\
\hline \multicolumn{4}{|l|}{$\mathrm{ABCC} 1$} \\
\hline Cyphoma gibbosum & gb|ACA53359.1| & $\mathrm{ABCC} 1$ & 63 \\
\hline Crassostrea gigas & gb|EKC19623.1| & Multidrug resistance-associated protein 1 & 59 \\
\hline Mytilus galloprovincialis & emb|CAX46412.2| & ABCC/MRP-like protein & 59 \\
\hline \multicolumn{4}{|l|}{ ABCG2 } \\
\hline Mytilus galloprovincialis & emb|CCD42044.1| & ABCG2-like & 83 \\
\hline Crassostrea gigas & gb|EKC19658.1| & ATP-binding cassette sub-family $\mathrm{G}$ member 2 & 81 \\
\hline
\end{tabular}




\subsection{Death, CI, and behavior of $C$. fluminea in response to FLX}

Over the $30 \mathrm{~d}$ of exposure, the mortality of each group was less than $2.5 \%$. There was no significant difference in $\mathrm{CI}$, which ranged from $33.8 \%$ to $38.2 \%$, between the treated groups and the respective controls.

Exposure to 0.5 and $5 \mu \mathrm{g} \mathrm{L}^{-1}$ FLX did not produce a statistically significant difference in siphoning behavior compared to control subjects. Filtration rates ranged from 16.52 to $19.27 \mathrm{~mL} / \mathrm{animal} / \mathrm{h}$. The filtration rates were significantly decreased by exposure to $50 \mu \mathrm{g} \mathrm{L}^{-1} \mathrm{FLX}(4.32 \pm 1.29 \mathrm{~mL} / \mathrm{animal} / \mathrm{h})(p<0.05$, Fig. 1$)$.

\subsection{MDA content and activity of SOD and CAT}

A significant downregulation of SOD activity in the gill and digestive gland was observed with 5 and $50 \mu \mathrm{g} \mathrm{L}^{-1}$ FLX treatments, while no significant changes were observed in the $0.5 \mu \mathrm{g} \mathrm{L}{ }^{-1}$ exposure group ( $p<0.05$, Fig. 2 A). Additionally, CAT activity was significantly upregulated in the gill and digestive gland in the 5 and $50 \mu \mathrm{g} \mathrm{L}^{-1}$ FLX-treated groups ( $p<0.05$, Fig. 2B). Moreover, significant increases in MDA levels were observed with 5 and $50 \mu \mathrm{g} \mathrm{L}^{-1}$ FLX treatments ( $p<0.05$, Fig. 2C).

\subsection{Expression of thioredoxin and glutathione system-related genes}

TR mRNA expression levels were elevated in the digestive gland by all FLX treatments ( $p<0.05$, Fig. 3A). However, the induction of TR mRNA in the gills was only observed with $50 \mu \mathrm{g} \mathrm{L}{ }^{-1}$ FLX treatment ( $p<0.05$, Fig. 3A). GR mRNA expression in the gills and digestive gland significantly decreased on exposure to 5 and $50 \mu \mathrm{g} \mathrm{L}^{-1}$ treatments $(p<0.05$, Fig. 3B). Additionally, significant induction of GPx mRNA was observed with $50 \mu \mathrm{g} \mathrm{L}^{-1}$ treatments in the gills $(p<0.05)$, whereas significant upregulation of GPx was observed in the digestive gland for all treatments (Fig. 3C). GSTpi mRNA levels in the gills and digestive gland were upregulated across all treatments (Fig. 3D).

\subsection{Transcription of $A B C$ transporter genes}

The transcript levels of $3 \mathrm{ABC}$ transporter genes $(A B C B 1, A B C C 1$, and $A B C G 2$ ) were evaluated after $30 \mathrm{~d}$ of exposure to FLX (Fig. 4). In

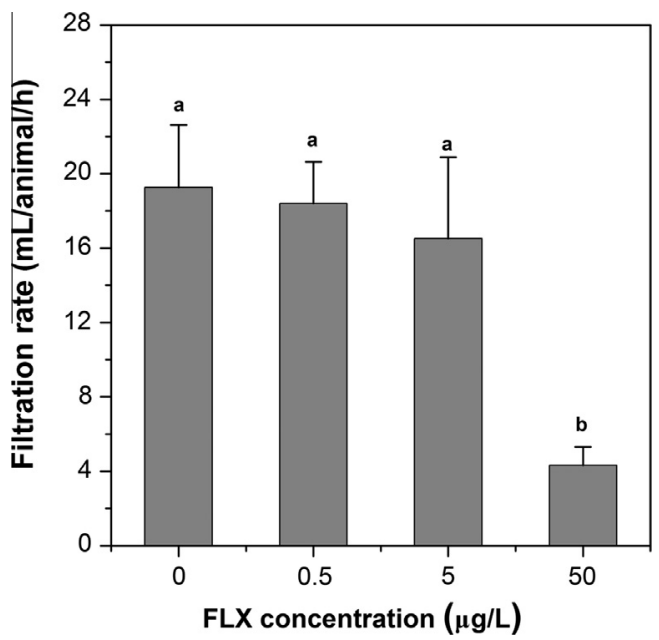

Fig. 1. Average $(n=5)$ filtration rate $(\mathrm{mL} / \mathrm{animal} / \mathrm{h})$ of $C$. fluminea in FLX-contaminated water containing $1 \mathrm{mg} \mathrm{L}^{-1}$ neutral red solution following exposure to the indicated FLX concentrations. The experiments were performed in triplicate and repeated 3 times with similar results. Data is expressed as mean \pm SEM. A statistically significant difference between treatment groups $(p<0.05,1$-way ANOVA) is indicated by differences in the letters above the bars.
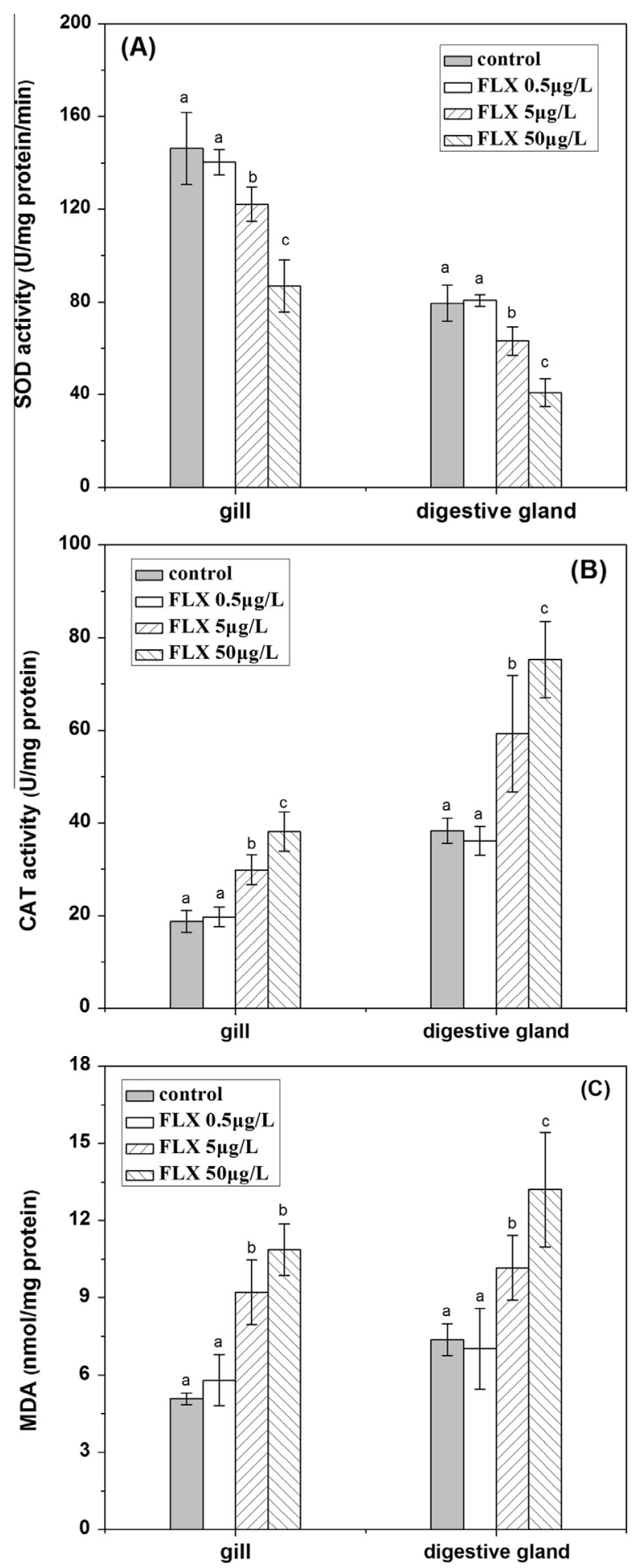

Fig. 2. Antioxidant enzyme activities and MDA levels in the gills and digestive gland from C. fluminea exposed to FLX. Shown in the figure are the SOD activity (A), CAT activity (B), and MDA levels in the gills and digestive gland (C). Data is expressed as mean \pm SEM $(n=6)$. A statistically significant difference between treatment groups ( $p<0.05,1$-way ANOVA) is indicated by differences in the letters above the bars.

the gills and digestive gland, levels of $A B C B 1$ and $A B C C 1$ were significantly downregulated following exposure to 5 and $50 \mu \mathrm{g} \mathrm{L}$ FLX ( $p<0.05$, Fig. $4 \mathrm{~A}$ and B). However, expression of the $A B C G 2$ transcript was significantly downregulated only in the $50 \mu \mathrm{g} \mathrm{L}^{-1}$ FLX treated group ( $p<0.05$, Fig. $4 C)$ in both tissues. 

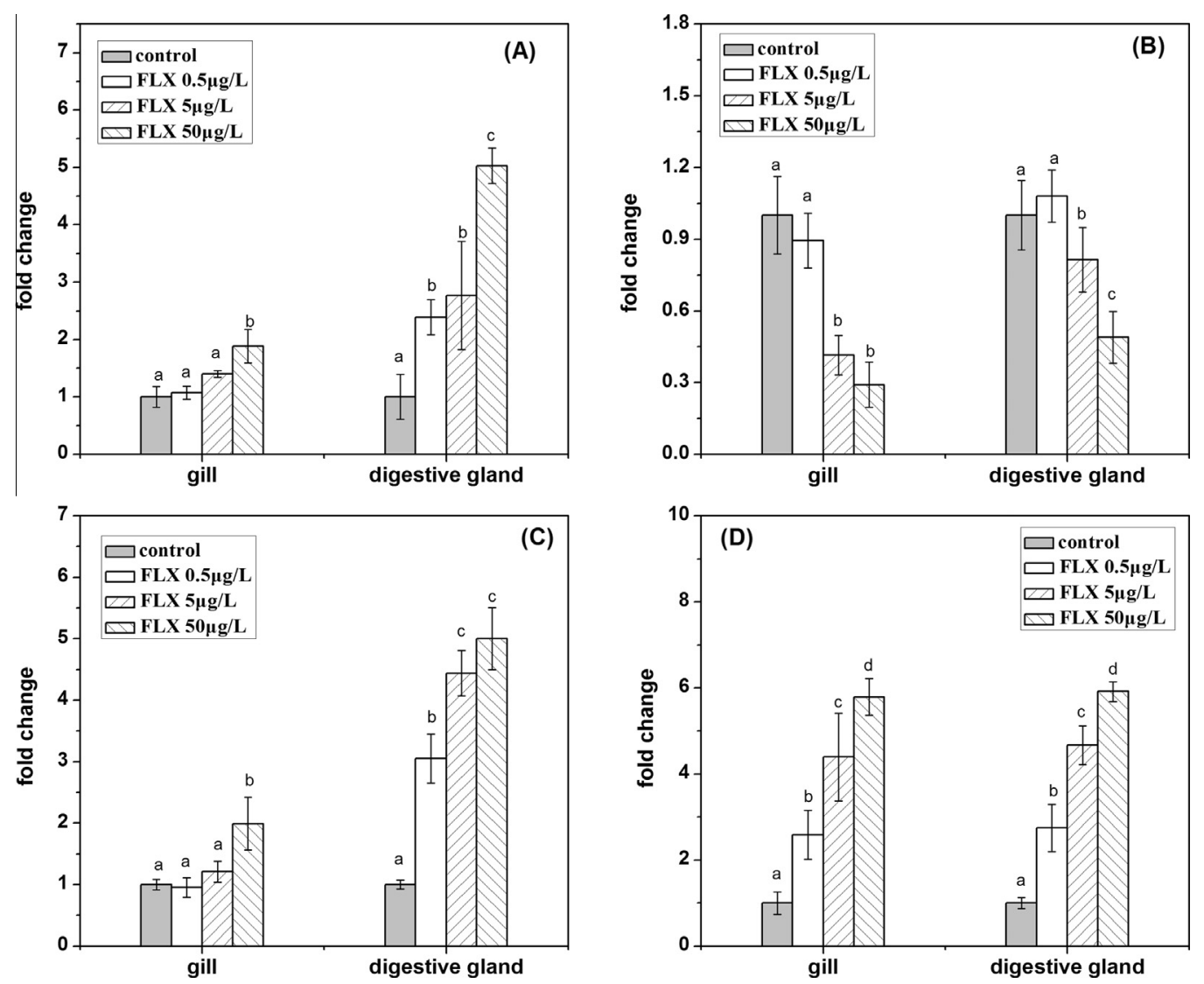

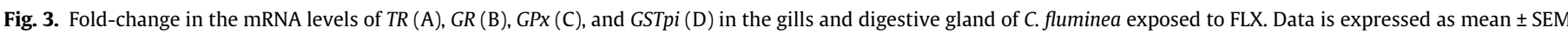
$(n=6)$. A statistically significant difference between treatment groups ( $p<0.05,1$-way ANOVA) is indicated by differences in the letters above the bars.

\section{Discussion}

In this study, 2 thioredoxin and glutathione enzymes system genes ( $T R$ and $G R$ ) and $3 A B C$ transporter genes $(A B C B 1, A B C C 1$, and $A B C G 2$ ) were cloned and identified firstly in $C$. fluminea. BLAST results revealed that the predicted amino acid sequences of GR and TR had high sequence identity with sequences from Crassostrea gigas. The identification of these genes provides the underlying basis for the cellular antioxidant system and cellular MXR system of $C$. fluminea in the transcript levels.

Bivalve siphons play an important role in nutritional physiology, defense, and reproductive mechanisms (Moulton et al., 1996). In the present study, the siphoning behavior of $C$. fluminea was inhibited by FLX. The inhibition of siphoning behavior observed in this study suggested that the health status of $C$. fluminea was reduced by FLX. Hazelton et al. (2013) reported that after a 67-d exposure to $22.3 \mu \mathrm{g} \mathrm{L}^{-1}$ FLX, the movement and burrowing behaviors of adult mussels ( $L$. fasciola) were inhibited. Previous studies have reported that 5-hydroxytryptamine (5-HT) may be a physiological regulator of siphon movements in the zebra mussel (Ram et al., 1999) and that the serotonin receptor is a primary neuroendocrine receptor in bivalves (Meechonkit et al., 2010). FLX increases extracellular 5-HT by inhibiting serotonin transport at nerve synapses (Lister et al., 2009). Therefore, inhibition of siphoning behavior in $C$. fluminea caused by FLX may due to its alteration of 5-HT signaling.

SOD and CAT are the primary enzymes of cellular antioxidant defense which can remove the ROS, such as surperoxide anion and hydrogen peroxide $\left(\mathrm{H}_{2} \mathrm{O}_{2}\right)$. SOD could reduce surpreoxide anion to $\mathrm{H}_{2} \mathrm{O}_{2}$, and then the $\mathrm{H}_{2} \mathrm{O}_{2}$ was converted to oxygen and water by CAT (Ren et al., 2013). In the present study, FLX (5 and
$50 \mu \mathrm{g} \mathrm{L}^{-1}$ ) significantly decreased SOD activity, but increased CAT activity, in the gills and digestive gland of $C$. fluminea. Inhibition of SOD activity and facilitation of CAT activity have also been observed in mice and $M$. galloprovincialis exposed to FLX (Djordjevic et al., 2011; Gonzalez-Rey and Bebianno, 2013). It is most likely that an increase in superoxide anions stimulated the consumption of SOD, and that CAT activity was induced by $\mathrm{H}_{2} \mathrm{O}_{2}$ formation in this study. We also assessed the MDA content in the clam tissues, since MDA is a biomarker of eraly phases of the oxidative stress response (Martin-Diaz et al., 2009). MDA content showed a significant increase in the gills and digestive gland of clams exposed to 5 and $50 \mu \mathrm{g} \mathrm{L}^{-1}$ FLX. These results indicate the ROS was excess, since MDA production is stimulated when ROS levels exceed the elimination capacity of antioxidant enzymes (Ren et al., 2013).

To better understand the oxidative stress caused by FLX, the transcript levels of four antioxidant enzymes of the thioredoxin and glutathione systems, TR, GR, GPx and GST were also evaluated in this study. The sequences of $T R$ and $G R$ were cloned and identified in C. fluminea firstly. TR is the only enzyme known to catalyze thioredoxin reduction and is a central component of the thioredoxin system that plays an important role in antioxidant balance (Mustacich and Powis, 2000; Arner and Holmgren, 2006). After $30 \mathrm{~d}$ FLX exposed, TR transcript levels were upregulated in the gills and digestive gland of $C$. fluminea, no significant differences were detected in the gills at the low FLX concentrations ( 0.5 and $\left.5 \mu \mathrm{g} \mathrm{L}^{-1}\right)$. The difference between the gills and digestive gland showed the digestive gland should play a more important role in the catalyze thioredoxin reduction. GR is an enzyme that reduces glutathione disulfide (GSSG) to the sulfhydryl form GSH, which is an important cellular antioxidant (Meister, 1988). The observed 

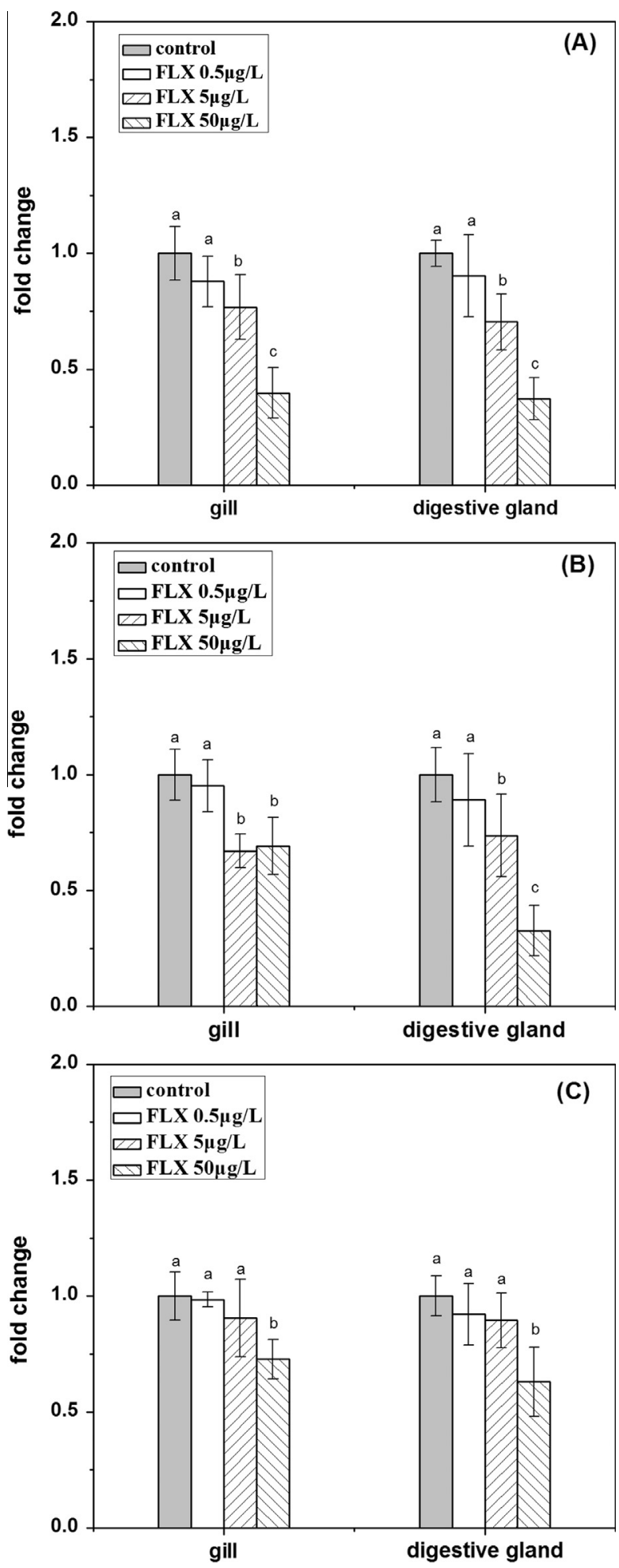

Fig. 4. Fold-change in the mRNA levels of $A B C B 1$ (A), $A B C C 1$ (B) and $A B C G 2$ (C) in the gills and digestive gland of $C$. fluminea exposed to FLX. Data is expressed as mean \pm SEM $(n=6)$. A statistically significant difference between treatment groups $(p<0.05,1$-way ANOVA) is indicated by differences in the letters above the bars.

decrease in GR activity after FLX exposed may also indicate increased ROS levels.

Phase II GST belongs to a family of multi-functional enzymes that promote the conjugation of reduced GSH with parental electrophilic compounds, which enable its transformation to more extractable hydrophilic metabolites (Halling-Sørensen et al., 1998).
The biological role of GPx is to protect the organism from oxidative damage. It can reduce lipid hydroperoxides to their corresponding alcohols and reduce free hydrogen peroxide to water (Ren et al., 2013). Glutathione system enzyme activity can be induced by pharmaceuticals in bivalves, such as $M$. galloprovincialis and $C$. fluminea (Contardo-Jara et al., 2011; Gonzalez-Rey and Bebianno, 2012, 2014; Martin-Diaz et al., 2009). In accordance with these studies, our data indicated that GPX and GSTpi levels were increased in the gills and digestive gland of $C$. fluminea after FLX treatment. The increase of GPx gene expression in the current study also indicated the production of ROS. Take all the biomarkers studied in this paper, our findings suggests that FLX enhanced the production of ROS and induces oxidative response in $C$. fluminea.

The MXR system acts as an outwardly directed energy-dependent transport system that removes endogenous and xenobiotic chemicals from the cell (Navarro et al., 2012), and plays a role in drug resistance, in addition to protecting tissues from xenobiotic accumulation (Leslie et al., 2005). Martin-Diaz et al. (2009) reported that exposure to 0.1 and $10 \mu \mathrm{g} \mathrm{L}^{-1}$ carbamazepine downregulated Pgp ( $A B C B 1)$ and Mrp2 ( $A B C C 2$ ) expression in the gills and digestive gland of $M$. galloprovincialis. In the current study, transcripts coding for primary MXR-related genes $A B C B 1, A B C C 1$, and $A B C G 2$ were downregulated by FLX in the gills and digestive gland. Our data showed that $A B C B 1$ and $A B C C 1$ are more sensitive than $A B C G 2$ to FLX, since $A B C G 2$ only significant decrease at the highest FLX concentrations. Previous studies showed that some pharmaceuticals and FLX are known to be inhibitors of mammalian ABCB and ABCC transporters (Peer et al., 2004; Caminada et al., 2008). Since the MXR system providing an active defense against environmental toxins, FLX may enhance its clinical application by reducing the potentialities of the MXR system. Interestingly, no significant inhibitory effects on P-gp1 and MRP-like transporters in fish were observed after FLX exposure (Caminada et al., 2008). Further study is needed to better understand the mechanism of MXR system in aquatic organisms.

\section{Conclusions}

In conclusion, the identification of thioredoxin and glutathione system enzymes and $\mathrm{ABC}$ transporter genes of $C$. fluminea provided the foundation for the study of its cellular antioxidant and MXR systems. Short-term ( $30 \mathrm{~d}$ ) exposure to FLX induced oxidative damage in $C$. fluminea. Furthermore, the significant downregulation of $A B C$ transporter genes suggested that FLX is a potent inhibitor of multixenobiotic defense in $C$. fluminea. Our results suggest that low dose and long time expose of FLX can exert adverse effects on the cellular detoxification and defense systems of $C$. fluminea.

\section{Acknowledgments}

This work was supported by the National Natural Science Foundation of China (21107131) and the National High-Tech R\&D Program (2012AA06A302).

\section{Appendix A. Supplementary material}

Supplementary data associated with this article can be found, in the online version, at http://dx.doi.org/10.1016/j.chemosphere. 2014.08.062.

\section{References}

Araujo, R., Moreno, D., Ramos, M., 1993. The Asiatic clam Corbicula fluminea (Müller, 1774) (Bivalvia: Corbiculidae) in Europe. Am. Malacol. Bull. 10, 39-49. 
Arner, E.S., Holmgren, A., 2006. The thioredoxin system in cancer. Semin. Cancer Biol. 16, 420-426.

Bard, S.M., 2000. Multixenobiotic resistance as a cellular defense mechanism in aquatic organisms. Aquat. Toxicol. 48, 357-389.

Batt, A.L., Kostich, M.S., Lazorchak, J.M., 2008. Analysis of ecologically relevant pharmaceuticals in wastewater and surface water using selective solid-phase extraction and UPLC-MS/MS. Anal. Chem. 80, 5021-5030.

Blair, B.D., Crago, J.P., Hedman, C.J., Klaper, R.D., 2013. Pharmaceuticals and personal care products found in the Great Lakes above concentrations of environmental concern. Chemosphere 93, 2116-2123.

Bringolf, R.B., Heltsley, R.M., Newton, T.J., Eads, C.B., Fraley, S.J., Shea, D., Cope, W.G., 2010. Environmental occurrence and reproductive effects of the pharmaceutical fluoxetine in native freshwater mussels. Environ. Toxicol. Chem. 29, 13111318.

Brooks, B.W., Foran, C.M., Richards, S.M., Weston, J., Turner, P.K., Stanley, J.K., Solomon, K.R., Slattery, M., La Point, T.W., 2003. Aquatic ecotoxicology of fluoxetine. Toxicol. Lett. 142, 169-183.

Caminada, D., Zaja, R., Smital, T., Fent, K., 2008. Human pharmaceuticals modulate P-gp1 (ABCB1) transport activity in the fish cell line PLHC-1. Aquat. Toxicol. 90, 214-222.

Carlsson, C., Johansson, A.K., Alvan, G., Bergman, K., Kuhler, T., 2006. Are pharmaceuticals potent environmental pollutants? Part I: environmental risk assessments of selected active pharmaceutical ingredients. Sci. Total Environ. $364,67-87$.

Chen, H., Zha, J., Liang, X., Bu, J., Wang, M., Wang, Z., 2013. Sequencing and de novo assembly of the Asian clam (Corbicula fluminea) transcriptome using the Illumina GAIIx method. Plos One 8, e79516.

Chen, H., Zha, J., Liang, X., Li, J., Wang, Z., 2014. Effects of the human antiepileptic drug carbamazepine on the behavior, biomarkers, and heat shock proteins in the Asian clam Corbicula fluminea. Aquat. Toxicol. 155C, 1-8.

Contardo-Jara, V., Pflugmacher, S., Wiegand, C., 2008. Multi-xenobiotic-resistance a possible explanation for the insensitivity of bivalves towards cyanobacterial toxins. Toxicon. 52, 936-943.

Contardo-Jara, V., Lorenz, C., Pflugmacher, S., Nutzmann, G., Kloas, W., Wiegand, C., 2011. Exposure to human pharmaceuticals Carbamazepine, Ibuprofen and Bezafibrate causes molecular effects in Dreissena polymorpha. Aquat. Toxicol. $105,428-437$.

Cooper, N.L., Bidwell, J.R., 2006. Cholinesterase inhibition and impacts on behavior of the Asian clam, Corbicula fluminea, after exposure to an organophosphate insecticide. Aquat. Toxicol. 76, 258-267.

Djordjevic, J., Djordjevic, A., Adzic, M., Elakovic, I., Matic, G., Radojcic, M.B., 2011. Fluoxetine affects antioxidant system and promotes apoptotic signaling in Wistar rat liver. Eur. J. Pharmacol. 659, 61-66.

Dzieweczynski, T.L., Hebert, O.L., 2012. Fluoxetine alters behavioral consistency of aggression and courtship in male Siamese fighting fish, Betta splendens. Physiol. Behav. 107, 92-97.

Epel, D., Luckenbach, T., Stevenson, C.N., MacManus-Spencer, L.A., Hamdoun, A., Smital, Tvrtko., 2008. Efflux transporters: newly appreciated roles in protection against pollutants. Environ. Sci. Technol. 42, 3914-3920.

Fent, K., Weston, A.A., Caminada, D., 2006. Ecotoxicology of human pharmaceuticals. Aquat. Toxicol. 76, 122-159.

Ferrari, B., Mons, R., Vollat, B., Fraysse, B., Paxeus, N., Lo Giudice, R., Pollio, A., Garric, J., 2004. Environmental risk assessment of six human pharmaceuticals: are the current environmental risk assessment procedures sufficient for the protection of the aquatic environment? Environ. Toxicol. Chem. 23, 1344-1354.

Ferrer, I., Thurman, E.M., 2012. Analysis of 100 pharmaceuticals and their degradates in water samples by liquid chromatography/quadrupole time-offlight mass spectrometry. J. Chromatogr. A 1259, 148-157.

Frenzel, M., Harrison, R.J., Harper, E.M., 2012. Nanostructure and crystallography of aberrant columnar vaterite in Corbicula fluminea (Mollusca). J. Struct. Biol. 178 8-18.

Gonzalez-Rey, M., Bebianno, M.J., 2012. Does non-steroidal anti-inflammatory (NSAID) ibuprofen induce antioxidant stress and endocrine disruption in mussel Mytilus galloprovincialis? Environ. Toxicol. Pharmacol. 33, 361-371.

Gonzalez-Rey, M., Bebianno, M.J., 2013. Does selective serotonin reuptake inhibitor (SSRI) fluoxetine affects mussel Mytilus galloprovincialis? Environ. Pollut. 173, 200-209.

Gonzalez-Rey, M., Bebianno, M.J., 2014. Effects of non-steroidal anti-inflammatory drug (NSAID) diclofenac exposure in mussel Mytilus galloprovincialis. Aquat. Toxicol. 148, 221-230.

Gros, M., Petrović, M., Barceló, D., 2006. Development of a multi-residue analytical methodology based on liquid chromatography-tandem mass spectrometry
(LC-MS/MS) for screening and trace level determination of pharmaceuticals in surface and wastewaters. Talanta 70, 678-690.

Halling-Sørensen, B., Nors Nielsen, S., Lanzky, P., Ingerslev, F., Holten Lützhøft, H., Jørgensen, S., 1998. Occurrence, fate and effects of pharmaceutical substances in the environment-a review. Chemosphere 36, 357-393.

Hazelton, P.D., Cope, W.G., Mosher, S., Pandolfo, T.J., Belden, J.B., Barnhart, M.C., Bringolf, R.B., 2013. Fluoxetine alters adult freshwater mussel behavior and larval metamorphosis. Sci. Total Environ. 445, 94-100.

Kim, Y., Choi, K., Jung, J., Park, S., Kim, P.-G., Park, J., 2007. Aquatic toxicity of acetaminophen, carbamazepine, cimetidine, diltiazem and six major sulfonamides, and their potential ecological risks in Korea. Environ. Int. 33 370-375.

Lazzara, R., Blazquez, M., Porte, C., Barata, C., 2012. Low environmental levels of fluoxetine induce spawning and changes in endogenous estradiol levels in the zebra mussel Dreissena polymorpha. Aquat. Toxicol. 106-107, 123-130.

Leslie, E.M., Deeley, R.G., Cole, S.P., 2005. Multidrug resistance proteins: role of Pglycoprotein, MRP1, MRP2, and BCRP (ABCG2) in tissue defense. Toxicol. Appl. Pharmacol. 204, 216-237.

Lister, A., Regan, C., Van Zwol, J., Van Der Kraak, G., 2009. Inhibition of egg production in zebrafish by fluoxetine and municipal effluents: a mechanistic evaluation. Aquat. Toxicol. 95, 320-329.

Liu, J.L., Wong, M.H., 2013. Pharmaceuticals and personal care products (PPCPs): a review on environmental contamination in China. Environ. Int. 59C, 208-224.

Marnett, L.J., 1999. Lipid peroxidation-DNA damage by malondialdehyde. Mutat. Res. 424, 83-95.

Martin-Diaz, L., Franzellitti, S., Buratti, S., Valbonesi, P., Capuzzo, A., Fabbri, E., 2009. Effects of environmental concentrations of the antiepilectic drug carbamazepine on biomarkers and cAMP-mediated cell signaling in the mussel Mytilus galloprovincialis. Aquat. Toxicol. 94, 177-185.

Meechonkit, P., Kovitvadhi, U., Chatchavalvanich, K., Sretarugsa, P., Weerachatyanukul, W., 2010. Localization of serotonin in neuronal ganglia of the freshwater pearl mussel, Hyriopsis (Hyriopsis) bialata. J. Mollus. Stud. 76 267-274.

Meister, A., 1988. Glutathione metabolism and its selective modification. J. Biol Chem. 263, 17205-17208.

Meister, A., Anderson, M.E., 1983. Glutathione. Ann. Rev. Biochem. 52, 711-760.

Metcalfe, C.D., Miao, X.S., Koenig, B.G., Struger, J., 2003. Distribution of acidic and neutral drugs in surface waters near sewage treatment plants in the lower Great Lakes. Can. Environ. Toxicol. Chem. 22, 2881-2889.

Moulton, C.A., Fleming, W.J., Purnell, C.E., 1996. Effects of two cholinesteraseinhibiting pesticides on freshwater mussels. Environ. Toxicol. Chem. 15, 131137.

Mustacich, D., Powis, G., 2000. Thioredoxin reductase. Biochem. J. 346, 1-8.

Navarro, A., Weißbach, S., Faria, M., Barata, C., Piña, B., Luckenbach, T., 2012. Abcb and Abcc transporter homologs are expressed and active in larvae and adults of zebra mussel and induced by chemical stress. Aquat. Toxicol. 122-123, 144152.

Peer, D., Dekel, Y., Melikhov, D., Margalit, R., 2004. Fluoxetine inhibits multidrug resistance extrusion pumps and enhances responses to chemotherapy in syngeneic and in human xenograft mouse tumor models. Cancer Res. 64, $7562-7569$.

Pery, A.R., Gust, M., Vollat, B., Mons, R., Ramil, M., Fink, G., Ternes, T., Garric, J., 2008 Fluoxetine effects assessment on the life cycle of aquatic invertebrates Chemosphere 73, 300-304.

Ram, J.L., Moore, D., Putchakayala, S., Paredes, A.A., Ma, D., Croll, R.P., 1999. Serotonergic responses of the siphons and adjacent mantle tissue of the zebra mussel, Dreissena polymorpha. Comp. Biochem. Physiol. C Pharmacol. Toxicol. Endocrinol. 124, 211-220.

Ren, J., Luo, J., Ma, H., Wang, X., Ma, L.Q., 2013. Bioavailability and oxidative stress of cadmium to Corbicula fluminea. Environ. Sci. Process Impacts 15, 860-869.

Sánchez-Argüello, P., Fernández, C., Tarazona, J.V., 2009. Assessing the effects of fluoxetine on Physa acuta (Gastropoda, Pulmonata) and Chironomus riparius (Insecta, Diptera) using a two-species water-sediment test. Sci. Total Environ. 407, 1937-1946.

Schmittgen, T.D., Livak, K.J., 2008. Analyzing real-time PCR data by the comparative C(T) method. Nat. Protoc. 3, 1101-1108.

Stancliffe, R.A., Thorpe, T., Zemel, M.B., 2011. Dairy attentuates oxidative and inflammatory stress in metabolic syndrome. Am. J. Clin. Nut. 94, 422-430.

Vasconcelos, V., Martins, J.C., Leao, P.N., 2009. Differential protein expression in Corbicula fluminea upon exposure to a Microcystis aeruginosa toxic strain. Toxicon. 53, 409-416. 